\title{
Application of entransy theory in the heat transfer optimization of flat-plate solar collectors
}

\author{
LI QinYi \& CHEN Qun*
}

Department of Engineering Mechanics, Key Laboratory for Thermal Science and Power Engineering of Ministry of Education, Tsinghua University, Beijing 100084, China

Received May 18, 2011; accepted September 7, 2011

\begin{abstract}
The flat-plate solar collector is an important component in solar-thermal systems, and its heat transfer optimization is of great significance in terms of the efficiency of energy utilization. However, most existing flat-plate collectors adopt metallic absorber plates with uniform thickness, which often works against energy conservation. In this paper, to achieve the optimal heat transfer performance, we optimized the thickness distribution of the absorber with the constraint of fixed total material volume employing entransy theory. We first established the correspondence between the collector efficiency and the loss of entransy, and then proposed the constrained extreme-value problem and deduced the optimization criterion, namely a uniform temperature gradient, employing a variational method. Finally, on the basis of the optimization criterion, we carried out numerical simulations, with the results showing remarkable optimization effects. When irradiation, the ambient temperature and the wind speed are $800 \mathrm{~W} / \mathrm{m}^{2}$, $300 \mathrm{~K}$ and $3 \mathrm{~m} / \mathrm{s}$, respectively, the collector efficiency is enhanced by $8.8 \%$ through optimization, which is equivalent to a copper saving of 30\%. We also applied the thickness distribution optimized for wind speed of $3 \mathrm{~m} / \mathrm{s}$ in heat transfer analysis with different wind speed conditions, and the collector efficiency was remarkably better than that for an absorber with uniform thickness.
\end{abstract}

flat-plate solar collectors, heat transfer performance, optimization, entransy theory

Citation: $\quad$ Li Q Y, Chen Q. Application of entransy theory in the heat transfer optimization of flat-plate solar collectors. Chin Sci Bull, 2012, 57: 299-306, doi: 10.1007/s11434-011-4811-6

As a common approach to utilize renewable energy, solar thermal utilization is an important way to conserve energy. The flat-plate solar collector is one of the most widely used key components of solar thermal utilization systems and has been a focus of research on renewable energy, with much research having analyzed and optimized its heat transfer. At present, methods of enhancing the heat transfer performance of flat-plate solar collectors fall into two categories [1-5]: one is raising the collector's effective absorption of irradiation and the other is minimizing the collector's heat loss to the environment. The first category includes optimizing the tilt angle of the collector and adopting a spectrum-selective transmission/absorption coating, while the second includes lowering the temperature of the absorber plate, adopting a transparent cover to induce a greenhouse effect, and adopt-

*Corresponding author (email: chenqun@tsinghua.edu.cn) ing high-heat-residence insulation.

To analyze theoretically and optimize the heat transfer performance of flat-plate collectors, several scholars [6-10] have applied exergy theory in the analysis of heat transfer for flat-plate collectors from the viewpoint of irreversibility in the heat transfer process. They studied the effects of different parameters on the exergy efficiency of collectors, and then selected better working parameters with higher exergy efficiency to achieve better heat transfer performance. However, most related research has only calculated the exergy efficiency of collectors under different working conditions with such given parameters as inlet/outlet temperatures and mass flow rates, and has not considered the optimal design of the collector's geometric structure using mathematical methods. Moreover, all existing flat-plate collectors have an absorber plate with uniform thickness. There has not yet been research on the optimal design of the 
absorber's thickness distribution to enhance the collector's performance.

To analyze and optimize heat transfer not involved in heat-work conversion, Guo et al. $[11,12]$ introduced a new physical quantity, entransy, to describe the heat transfer capacity of an object or a system, and proposed the concept of entransy dissipation to measure the loss of such capacity during the process. Moreover, Guo et al. proposed the entransy dissipation extremum principle to optimize the processes of heat conduction [11-15], heat convection [16,17], and thermal radiation [18].

The present paper applies entransy theory to the heat transfer optimization of flat-plate collectors. The thickness distribution of the absorber plate is optimized for a fixed absorber volume. The relation between the collector's performance and the entransy loss is theoretically established. Furthermore, the constrained extreme-value problem is proposed and the governing equation of the optimization is deduced employing a variational method. Finally, the optimal design of the thickness distribution of an absorber is numerically implemented on the basis of the governing equation to maximize the collector efficiency under certain constraint conditions.

\section{Heat transfer model for flat-plate collectors}

Figure 1 shows the typical structure of a flat-plate solar collector. The flat-plate collector is composed of an absorber plate, fluid tubes, insulation, casing and transparent covers. The present paper only considers flat-plate collectors without transparent covers for simplicity.

As the main component of flat-plate collectors, the absorber plate absorbs irradiation and transfers the gained heat to the fluid in the tubes through heat conduction and convection. Figure 2 is a schematic diagram of the geometric structure of the absorber plate and the corresponding coordinate system, where $L$ presents the length of the fluid tube, $2 W$ is the width between tubes, $t_{p}$ is the thickness of the absorber, and $m$ is the rate of mass flow through a single fluid tube. Owing to symmetry, the heat transfer process within the domain $(0<y<L, 0<x<W)$ is studied.

Since the thickness of the absorber plate is far less than its length and width, heat conduction within the absorber can be simplified as two-dimensional steady-state heat conduction with a constant internal heat source and an internal heat sink varying with the temperature field. The energy conservation equation is expressed as

$$
\begin{aligned}
& k_{p}\left[\frac{\partial}{\partial x}\left(t_{p}(x, y) \frac{\partial T_{p}(x, y)}{\partial x}\right)+\frac{\partial}{\partial y}\left(t_{p}(x, y) \frac{\partial T_{p}(x, y)}{\partial y}\right)\right] \\
& \quad+S-Q_{\text {Loss }}(x, y)=0,
\end{aligned}
$$

where $T_{p}(x, y)$ is the temperature of the absorber, $t_{p}(x, y)$ is the thickness of the absorber, $k_{p}$ is the conductivity of the absorber, $S$ is the irradiation actually absorbed in the unit

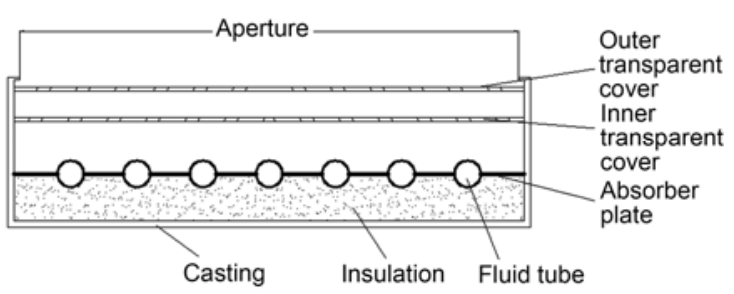

Figure 1 Schematic diagram of the flat-plate collector.

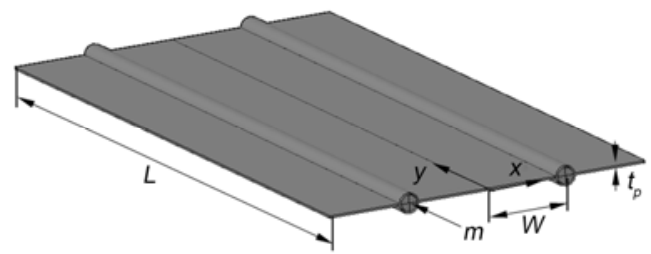

Figure 2 Schematic diagram of the absorber model and the coordinate system.

absorber area, and $Q_{\mathrm{Loss}}(x, y)$ is the heat loss in the unit absorber area.

The expression for the actually absorbed irradiation in the unit absorber area is

$$
S=\alpha I,
$$

where $\alpha$ is the visible absorption rate of the absorber surface and $I$ is solar radiation intensity.

The expression for the heat loss in the unit absorber area is [1]

$$
Q_{\text {Loss }}(x, y)=U_{L}\left(T_{p}(x, y)-T_{a}\right),
$$

where $T_{a}$ is ambient temperature and $U_{L}$ is the total heat loss coefficient.

The total heat loss coefficient $U_{L}$ consists of the top heat loss coefficient $U_{t}$ and the bottom heat loss coefficient $U_{b}$ :

$$
U_{L}=U_{t}+U_{b} \text {. }
$$

The expression for the coefficient $U_{b}$ of the bottom heat loss through insulation conduction to the environment is

$$
U_{b}=\frac{k_{\text {ins }}}{X_{\text {ins }}},
$$

where $X_{\text {ins }}$ is the thickness of insulation and $k_{\text {ins }}$ is the conductivity of the insulation.

The expression for the top heat loss coefficient $U_{t}$ is

$$
U_{t}=h_{r}+h_{\text {conv }},
$$

where $h_{r}$ is the coefficient of top heat loss through thermal radiation, and $h_{\text {conv }}$ is the coefficient of top heat loss through convective heat transfer.

The expression for $h_{r}$ can be obtained by analyzing the thermal radiation process for a tiny object and infinite space [1]:

$$
h_{r}=\varepsilon_{p} \sigma\left(T_{p}^{2}+T_{a}^{2}\right)\left(T_{p}+T_{a}\right),
$$

where $\varepsilon_{p}$ is the infrared emittance of the absorber surface and $\sigma$ is the Stefan-Boltzmann constant. 
The coefficient $h_{\text {conv }}$ of top heat loss through convective heat transfer is related to the local wind speed $V$ and can be calculated using an empirical equation $[1,2]$ :

$$
h_{\text {conv }}=2.8+3 \mathrm{~V} \text {. }
$$

From eqs. (2)-(8), the source term of the energy conservation equation can be calculated. The source term is a field function that depends on the temperature field.

For the boundary conditions of the heat-conduction equation, $y=0$ and $y=L$, heat is conducted through insulation to the environment, i.e.,

$$
\frac{\partial T_{p}}{\partial y}=\frac{k_{\mathrm{ins}}\left(T_{p}-T_{a}\right)}{X_{\mathrm{ins}} k_{p}}(y=0) .
$$

and

$$
\frac{\partial T_{p}}{\partial y}=-\frac{k_{\mathrm{ins}}\left(T_{p}-T_{a}\right)}{X_{\mathrm{ins}} k_{p}}(y=L) .
$$

$x=0$ is a symmetric boundary:

$$
\frac{\partial T_{p}}{\partial x}=0
$$

At $x=W$, there is a boundary condition of convective heat transfer:

$$
\frac{\partial T_{p}}{\partial x}=-\frac{h_{f e}}{k_{p}}\left(T_{p}-T_{f}(y)\right),
$$

where $h_{f e}$ is the coefficient of the equivalent convective heat transfer between the absorber and the working fluid, and $T_{f}(y)$ is the fluid temperature.

The equivalent convective heat transfer coefficient $h_{f e}$ can be written as [19]

$$
h_{f e}=\frac{1}{t_{p}}\left[\frac{\pi d_{i} h_{f}}{2}+\frac{\pi d_{o} U_{L}\left(T_{p}-T_{a}\right)}{4\left(T_{p}-T_{f}\right)}-\frac{d_{o} S}{2\left(T_{p}-T_{f}\right)}\right],
$$

where $d_{o}$ and $d_{i}$ are the outer diameter and inner diameter of the fluid tube, respectively, and $h_{f}$ is the convective heat transfer coefficient for a circular tube with non-uniform surface temperature.

The convective heat transfer between the fluid tube and fluid is a combined process of natural and forced convections, and the surface temperature changes significantly both in the axial and circumferential directions. For this convective heat transfer, Oliver [20] provided an empirical equation to calculate the averaged Nusselt number $N u_{m}$ of the mixed convective heat transfer in horizontal circular tubes based on a massive number of experimental results:

$$
\begin{gathered}
N u_{m}=1.75\left(\frac{\mu_{b}}{\mu_{w}}\right)^{0.14}\left[G z_{m}+0.0083\left(G r_{m} P r_{m}\right)^{0.75}\right]^{\frac{1}{3}} \\
\left(L / d_{i}>70\right),
\end{gathered}
$$

where $G z_{m}, G r_{m}$, and $P r_{m}$ are the averaged Graetz number, the averaged Grashof number and the averaged Prandtl number, respectively, and $\mu_{b}$ and $\mu_{w}$ are the dynamic viscos- ities of the fluid at bulk and surface temperatures, respectively.

Using $k_{f}$ as the conductivity of the fluid, the expression for $h_{f}$ is

$$
h_{f}=\frac{k_{f} N u_{m}}{d_{i}} .
$$

An expression for the fluid temperature distribution is obtained by establishing the energy conservation equation for the fluid element [19]:

$$
\begin{aligned}
& T_{f}(y)= \\
& T_{\text {in }}+\frac{2}{m c_{p}} \int_{0}^{y}\left[-k_{p} t_{p} \frac{\partial T_{p}}{\partial x}+\frac{d_{o} S}{2}-\frac{\pi d_{o} U_{L}\left(T_{p}-T_{a}\right)}{4}\right]_{x=W} \mathrm{~d} y,
\end{aligned}
$$

where $T_{\text {in }}$ is the fluid inlet temperature, $m$ is the fluid mass flow, and $c_{p}$ is the specific heat at constant pressure for the fluid.

From eqs. (1)-(16), the heat conduction of the absorber can be numerically simulated.

\section{Analysis and optimization of the absorber with entransy theory}

\subsection{Entransy analysis of the absorber}

Multiplying the energy conservation equation, eq. (1), with the local temperature $T_{p}$, the entransy balance equation of the heat conduction process within the absorber is obtained as

$$
S T_{p}-U_{L}\left(T_{p}-T_{a}\right) T_{p}-\nabla \cdot\left(t_{p} q T_{p}\right)+t_{p} q \cdot \nabla T_{p}=0,
$$

where $q$ is the heat flux density. The expression for $q$ is

$$
q=-k_{p} \nabla T_{p} .
$$

In eq. (17), the first term on the left is the product of the absorbed irradiation and the absorber temperature, representing the entransy input flow from solar radiation. The second term is the product of the heat loss and the absorber temperature, representing the entransy loss of the absorber due to heat loss. The third term represents the entransy transportation within the absorber. The fourth term is the entransy dissipation term, which represents the entransy loss due to heat conduction for finite temperature differences.

Integrating eq. (17) throughout the whole heat-conduction domain $\Omega$ and transforming the divergence term to boundary integration using the Gauss formulas gives

$$
\begin{aligned}
& \iint_{\Omega}\left(S T_{p}-U_{L}\left(T_{p}-T_{a}\right) T_{p}-k_{p} t_{p} \nabla T_{p} \cdot \nabla T_{p}\right) \mathrm{d} A \\
& =\oint_{\Gamma}\left(t_{p} q_{\Gamma} T_{p}\right) \cdot n \mathrm{~d} S,
\end{aligned}
$$

where $\Gamma$ represents the absorber boundary. According to eq. (19), the obtained entransy flow from solar radiation minus the entransy loss due to heat loss and the entransy dissipation during heat conduction (as shown on the left of 
the equation) equals the entransy flow transferred out through the absorber boundaries (as shown on the right of the equation).

At the symmetric boundary $x=0, q_{\Gamma}=0$; at the boundaries $y=0$ and $y=L$, heat is transferred to the environment through insulation conduction, which can also be regarded as an adiabatic boundary, i.e., $q_{\Gamma}=0$. Therefore, all entransy flows within the absorber are transferred into the working fluid through the convective-heat-transfer boundary and transformed into the entransy of the fluid. By contrast, the geometric scale of the fluid tube is far less than that of the absorber and the temperature gradient in the fluid tube is not as significant; therefore, entransy dissipation due to convective heat transfer in the fluid tube can be ignored compared with the entransy dissipation due to heat conduction within the absorber plate. As a result, the boundary integration on the right of eq. (19) equals the entransy increment rate of the working fluid $\Delta G$ :

$$
\Delta G=\frac{1}{2} m c_{p}\left(T_{\text {out }}^{2}-T_{\text {in }}^{2}\right)=\oint_{\Gamma}\left(t_{p} q_{\Gamma} T_{p}\right) \cdot n \mathrm{~d} S,
$$

where $T_{\text {in }}$ and $T_{\text {out }}$ are the inlet and outlet temperatures of the fluid, respectively, $m$ is the fluid mass flow rate, and $c_{p}$ is the specific heat at constant pressure of the fluid. Eq. (20) represents not only the quantity of the fluid's gained energy in unit time but also the quality of the gained energy.

Substituting eq. (20) into eq. (19), we obtain

$$
\begin{aligned}
& \iint_{\Omega}\left(S T_{p}-U_{L}\left(T_{p}-T_{a}\right) T_{p}-k_{p} t_{p} \nabla T_{p} \cdot \nabla T_{p}\right) \mathrm{d} A \\
& =\frac{1}{2} m c_{p}\left(T_{\text {out }}^{2}-T_{\text {in }}^{2}\right) .
\end{aligned}
$$

It is clear that the maximization of the obtained entransy flow from solar radiation minus both the entransy loss due to heat loss to the environment and entransy dissipation due to the absorber's heat conduction leads to the maximization of the entransy increment rate of the working fluid; i.e., the optimum heat transfer performance of the collector.

\subsection{Optimization criterion for the design of the ab- sorber's thickness distribution}

According to eq. (21), the optimization problem of the absorber's thickness distribution can be described as the following constrained extreme-value problem.

(1) Optimization objective: the maximization of the obtained entransy flow from solar radiation minus both the entransy loss due to heat loss to the environment and entransy dissipation due to the absorber's heat conduction. Employing the variation method, this can be stated as

$$
\delta \iint_{\Omega}\left(S T_{p}-U_{L}\left(T_{p}-T_{a}\right) T_{p}-k_{p} t_{p} \nabla T_{p} \cdot \nabla T_{p}\right) \mathrm{d} A=0 .
$$

(2) Optimization object: the absorber's thickness distribution $t_{p}(x, y)$.
(3) Constraint conditions: a) the total volume of the absorber is fixed, i.e.,

$$
\iint_{\Omega} t_{p}(x, y) \mathrm{d} A=\text { const },
$$

b) the heat-conduction differential equation, eq. (1).

The corresponding functional can be constructed applying the Lagrange multiplier method to eliminate the constraint conditions:

$$
\begin{aligned}
\Pi & =\iint_{\Omega}\left(-k_{p} t_{p} \nabla T_{p} \cdot \nabla T_{p}+T_{p}\left(S+U_{L} T_{a}\right)-U_{L} T_{p}^{2}\right) \mathrm{d} A \\
& +B \iint_{\Omega} t_{p}(x, y) \mathrm{d} A+\iint_{\Omega} C\left(k_{p} \nabla \cdot\left(t_{p} \nabla T_{p}\right)\right. \\
& \left.+S-U_{L}\left(T_{p}-T_{a}\right)\right) \mathrm{d} A,
\end{aligned}
$$

where $B$ and $C$ are Lagrange multipliers. Because eq. (23) is an isoperimetric boundary condition, $B$ remains constant, while $C$ is a field variable.

The variation of eq. (24) with respect to temperature $T_{p}$ gives

$$
\nabla \cdot\left(t_{p} \nabla C\right)-S-U_{L} T_{a}-C U_{L}=0 .
$$

One solution of eq. (25) is

$$
C=-\frac{S+U_{L} T_{a}}{U_{L}} .
$$

Substituting the constant solution of $C$ into the expression for the functional and the variation with respect to thickness $t_{p}$ gives

$$
\left|\nabla T_{p}\right|^{2}=\frac{B}{k_{p}}=\text { const } .
$$

Therefore, the optimum distribution of the absorber's thickness should guarantee a uniform temperature gradient field within the absorber. Because of the constant value of the conductivity, a uniform temperature gradient implies uniform heat flux density. In other words, the absorber's thickness should be proportional to the heat flux, which is the optimization criterion for the design of the thickness distribution.

\subsection{Optimization algorithm}

Numerically arranging more absorber material (e.g., copper) where the heat flux is greater can ensure a sufficiently uniform temperature gradient field and an optimal thickness distribution. The optimization algorithm is as follows [14].

(1) Initialize the absorber's thickness distribution; usually uniform thickness is used.

(2) Numerically solve the heat-conduction differential equation to obtain the absorber's temperature field and temperature gradient field.

(3) Solve the new thickness field according to 


$$
t_{p}^{(n+1)}(x, y)=\frac{\left|t_{p}^{(n)}(x, y) \nabla T_{p}(x, y)\right|}{\iint_{\Omega}\left|t_{p}^{(n)}(x, y) \nabla T_{p}(x, y)\right| \mathrm{d} A} t_{p m} A_{c}
$$

where $t_{p m}$ is the average thickness of the absorber, $A_{c}$ is the absorber area, and the superscripts $(n)$ and $(n+1)$ respectively represent the $n$th and $(n+1)$ th iteration results. It is obvious that when two adjacent iteration results are equal, the temperature gradient is constant.

(1) Return to step (2) and recalculate the temperature field and the temperature gradient field until

$$
\frac{\left|t_{p}^{(n+1)}(x, y)-t_{p}^{(n)}(x, y)\right|}{t_{p}^{(n+1)}(x, y)}<\mathrm{err},
$$

where err is the given convergence tolerance.

In practical simulation, to avoid the absorber being too thin, a minimum base thickness $t_{p b}$ is given and the volume $\left(t_{p m}-t_{p b}\right) A_{c}$ is used in the optimization of the thickness arrangement.

\section{Numerical simulations and results analyses}

Table 1 gives the geometric parameters and physical properties of the flat-plate collector, including the conductivity, absorptivity, and emissivity of the absorber material (copper) and the thickness and conductivity of the insulation. Table 2 gives the physical properties of the working fluid (water) such as the specific heat at constant pressure, conductivity, expansion coefficient, dynamic viscosity and $\operatorname{Pr}$ number, as well as operation parameters such as the mass flow rate and inlet temperature. Table 3 gives environmental parameters, namely the solar radiation intensity, ambient temperature

Table 1 Geometric parameters and physical properties of the flat-plate collector

\begin{tabular}{cc}
\hline Parameter & Value \\
\hline Length of the fluid tube $L$ & $2 \mathrm{~m}$ \\
Width between tubes $2 W$ & $0.4 \mathrm{~m}$ \\
Average thickness of the absorber $t_{p m}$ & $0.5 \mathrm{~mm}$ \\
Outer diameter of the fluid tube $d_{o}$ & $0.011 \mathrm{~m}$ \\
Inner diameter of the fluid tube $d_{i}$ & $0.01 \mathrm{~m}$ \\
Insulation thickness $X_{\text {ins }}$ & $0.05 \mathrm{~m}$ \\
Insulation conductivity $k_{\text {ins }}$ & $0.04 \mathrm{~W} / \mathrm{m}^{2}$ \\
Absorber (copper) conductivity $k_{p}$ & $385 \mathrm{~W} / \mathrm{m}^{2}$ \\
Absorber (copper) absorptivity $\alpha$ & 0.9 \\
Absorber (copper) emissivity $\varepsilon_{p}$ & 0.17 \\
\hline
\end{tabular}

Table 2 Physical properties and operation parameters of the working fluid

\begin{tabular}{cc}
\hline Parameter & Value \\
\hline Specific heat of the working fluid (water) $c_{p}$ & $4180 \mathrm{~J} /(\mathrm{kg} \mathrm{K})$ \\
Prandtl number of the working fluid (water) $P r$ & 4.34 \\
Dynamic viscosity of the working fluid (water) $v$ & $0.6 \times 10^{-6} \mathrm{~m}^{2} / \mathrm{s}$ \\
Expansion coefficient of the working fluid (water) $\beta$ & $1.8 \times 10^{-4} \mathrm{~K}^{-1}$ \\
Inlet temperature of the fluid $T_{\text {in }}$ & $305 \mathrm{~K}$ \\
Mass flow rate $m$ & $0.003 \mathrm{~kg} / \mathrm{s}$ \\
\hline
\end{tabular}

Table 3 Environmental parameters

\begin{tabular}{cc}
\hline Parameter & Value \\
\hline Solar radiation intensity $I$ & $800 \mathrm{~W} / \mathrm{m}^{2}$ \\
Ambient temperature $T_{a}$ & $300 \mathrm{~K}$ \\
Wind speed $V$ & $3 \mathrm{~m} / \mathrm{s}$ \\
\hline
\end{tabular}

and wind speed.

FLUENT12.1 software is used to carry out the numerical simulations to solve the energy conservation equation and optimize the thickness distribution. The complex internal heat source/sink and boundary conditions are introduced using the UDF (User Defined Functions) function, and the iteration convergence tolerance is taken to be $1 \times 10^{-8}$.

\subsection{Validation of the simulation of the temperature field}

To validate the simulation method for the temperature field, a simplified heat conduction process is studied where the absorber is of uniform thickness and there is a constant heat source $S$, and three boundary conditions are adiabatic while the fourth boundary condition is convective heat transfer. The analytic solution for temperature in this case is

$$
\begin{aligned}
& T_{p}(x, y)=\frac{S}{2 k_{p} t_{p}}\left(W^{2}-x^{2}\right)+\frac{S}{h_{f} t_{p}} W+\frac{T_{\text {out }}+T_{\text {in }}}{2} \\
& \quad+\sum_{k=1}^{\infty} A_{2 k-1} \cosh \left(\frac{(2 k-1) \pi}{L} x\right) \cos \left(\frac{(2 k-1) \pi}{L} y\right), \\
& A_{2 k-1}= \\
& {[(2 k-1) \pi]^{2}\left[\cosh \left(\frac{(2 k-1) \pi}{L} W\right)+\frac{k_{p}(2 k-1) \pi}{L h_{f}} \sinh \left(\frac{(2 k-1) \pi}{L} W\right)\right]}
\end{aligned}
$$$$
A_{2 k-1}=
$$

Here, a linear fluid temperature distribution is assumed, and the convective-heat-transfer coefficient $h_{f}$ is supposed to be constant. The parameters are an outlet temperature $T_{\text {out }}$ $=325 \mathrm{~K}$, inlet temperature $T_{\text {in }}=305 \mathrm{~K}, S=720 \mathrm{~W} / \mathrm{m}^{2}, k_{p}=$ $385 \mathrm{~W} /(\mathrm{m} \mathrm{K}), t_{p}=0.5 \mathrm{~mm}, W=0.2 \mathrm{~m}, L=2 \mathrm{~m}$, and $h_{f}=$ $60000 \mathrm{~W} /\left(\mathrm{m}^{2} \mathrm{~K}\right)$.

Figures 3 and 4 respectively give the temperature field contours according to numerical results and analytical results. It is seen from the figures that the numerical and analytical results are in exact accordance, which validates the numerical methods of the present paper.

\subsection{Optimization results and analyses}

The optimal design of the absorber's thickness is implemented using the optimization algorithm stated above. The average thickness of the absorber is given as $0.5 \mathrm{~mm}$ and the minimum thickness is given as $0.01 \mathrm{~mm}$ to avoid the absorber being too thin.

Table 4 lists values of important parameters before and after optimization. These parameters are the outlet temperature $T_{\text {out }}$, difference between the absorber's average temperature and the ambient temperature $\left(T_{p m}-T_{a}\right)$, collector 


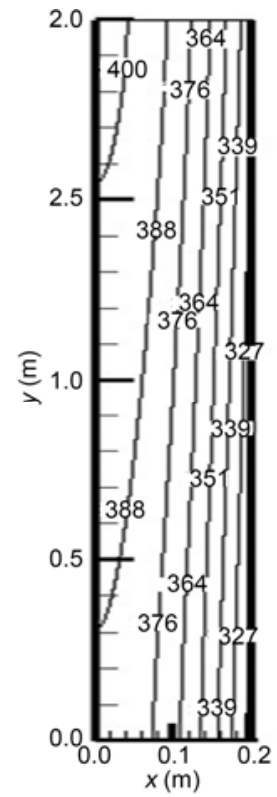

Figure 3 Numerical solution of the temperature field (Unit: K)

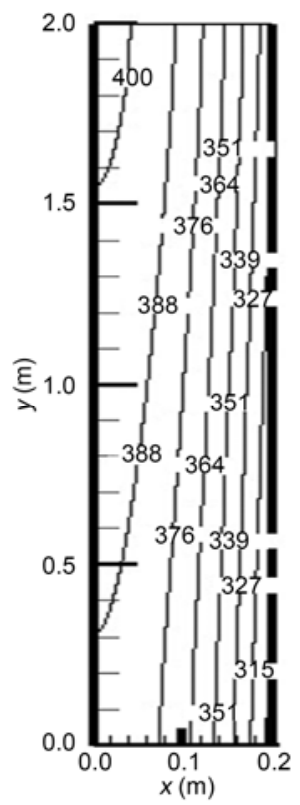

Figure 4 Analytical solution of the temperature field (Unit: K)

efficiency $\eta$, and entransy increment rate for the fluid $\Delta G$. The definition of the collector efficiency is

$$
\eta=\frac{m c_{p}\left(T_{\text {out }}-T_{\text {in }}\right)}{I A_{c}},
$$

where $I$ is the solar radiation intensity, $A_{c}$ is the absorber area, $m$ is the mass flow rate, and $c_{p}$ is the specific heat.

According to Table 4, the collector efficiency increases $8.8 \%$ and the fluid's entransy increment rate increases by $9.1 \%$ with optimization. If a uniform thickness is adopted, to achieve $32.8 \%$ collector efficiency, a copper plate at least $0.71 \mathrm{~mm}$ thick needs to be used, while the same collector
Table 4 Comparison of results before and after optimization using entransy theory

\begin{tabular}{|c|c|c|c|c|}
\hline & $T_{\text {out }}\left({ }^{\circ} \mathrm{C}\right)$ & $T_{p m}-T_{a}\left({ }^{\circ} \mathrm{C}\right)$ & $\eta(\%)$ & $\Delta G\left(10^{4} \mathrm{~W} \mathrm{~K}\right)$ \\
\hline Before optimization & 47.6 & 34.6 & 30.16 & 6.18 \\
\hline After optimization & 50.0 & 33.1 & $\begin{array}{c}32.80 \\
(\uparrow 8.8 \%)\end{array}$ & $\begin{array}{c}6.74 \\
(\uparrow 9.1 \%)\end{array}$ \\
\hline
\end{tabular}

efficiency can be achieved with a copper plate only $0.5 \mathrm{~mm}$ thick on average after optimization. Thus, a copper saving of up to $30 \%$ is achieved.

Figures 5 and 6 respectively give the temperature field and temperature gradient field before and after optimization. Before optimization, the temperature gradient is close to zero near the symmetric boundary, and reaches a maximum $(311.3 \mathrm{~K} / \mathrm{m})$ at the fluid inlet, and the temperature gradient field is far from uniform. After optimization, the temperature gradient is constant at $110.1 \mathrm{~K} / \mathrm{m}$ throughout most of the absorber domain. It is seen by comparing the temperature solutions before and after optimization that the temperature gradient field within the absorber is obviously more uniform after optimization than before optimization, and this explains the enhancement of the collector's performance.

Figure 7 is a contour map of the absorber's thickness distribution after optimization. In the figure, the absorber is thicker closer to the fluid tube and to the inlet end. This is because the thickness distribution is proportional to the heat flux, and the heat flux is greater near the fluid tube and the inlet end, where stronger heat conduction is expected. The maximum thickness of $1.8 \mathrm{~mm}$ is at the fluid inlet. Near the symmetric boundary, the heat flux is extremely low and the
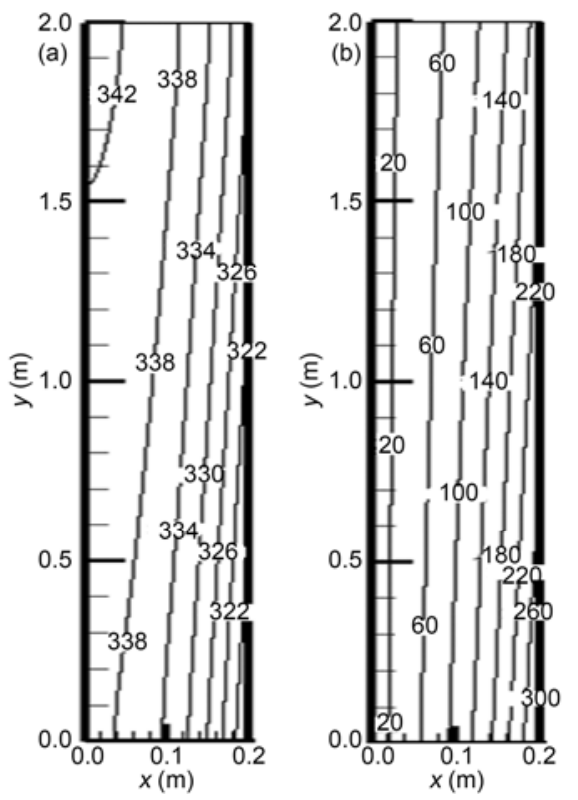

Figure 5 Simulation results before optimization. (a) Temperature field (Unit: K); (b) temperature gradient field (Unit: $\mathrm{K} / \mathrm{m}$ ). 

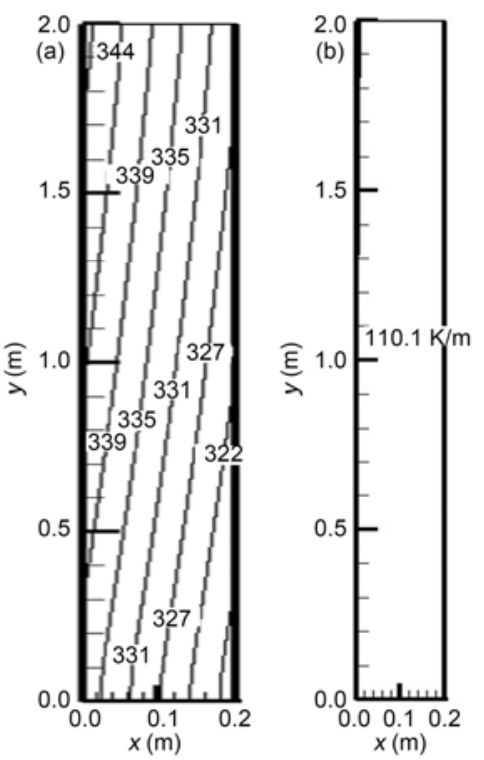

Figure 6 Simulation results after optimization. (a) Temperature field (Unit: K); (b) temperature gradient field (Unit: $\mathrm{K} / \mathrm{m}$ ).

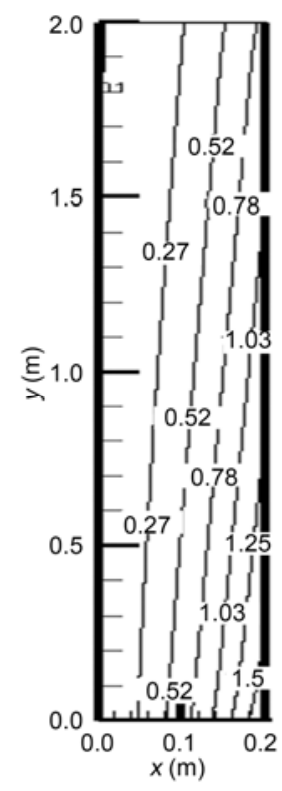

Figure 7 Thickness distribution of the absorber (Unit of thickness: $\mathrm{mm}$ ).

thickness is almost the same as the given minimum thickness, $0.01 \mathrm{~mm}$.

To study the performance of the above thickness distribution for different wind speeds, numerical simulations are also carried out for the absorber with uniform thickness of $0.5 \mathrm{~mm}$ and an absorber with a thickness distribution optimized for a wind speed of $3 \mathrm{~m} / \mathrm{s}$, where the wind speed is varied among 1,2 and $4 \mathrm{~m} / \mathrm{s}$ in the simulations while the other operation parameters are kept the same. Table 5 gives the simulation results, showing that the absorber with the thickness distribution optimized for a wind speed of $3 \mathrm{~m} / \mathrm{s}$ also significantly performs better than the absorber with
Table 5 Collector efficiency for various wind speeds

\begin{tabular}{ccccc}
\hline Wind speed $V(\mathrm{~m} / \mathrm{s})$ & 1 & 2 & 3 & 4 \\
\hline $\begin{array}{c}\text { Collector efficiency } \eta \\
(\%) \text { (uniform thickness) }\end{array}$ & 42.01 & 35.12 & 30.16 & 25.32 \\
& & & & \\
$\begin{array}{c}\text { Collector efficiency } \eta \\
(\%)(\text { optimized thickness }\end{array}$ & 45.48 & 38.24 & 32.80 & 28.66 \\
under 3 m/s wind speed) & $(\uparrow 8.3 \%)$ & $(\uparrow 8.9 \%)$ & $(\uparrow 8.8 \%)$ & $(\uparrow 13.2 \%)$ \\
\hline
\end{tabular}

uniform thickness when the wind speed changes in the range of $1-4 \mathrm{~m} / \mathrm{s}$, and that the collector efficiency for the optimized thickness distribution is $8.3 \%-13.2 \%$ greater than that for the uniform-thickness absorber with changing wind speeds.

\section{Conclusions}

The present paper applied entransy theory in the analysis of the absorber's heat conduction and the optimal design of the absorber's thickness distribution. Combining the twodimensional energy conservation equation for the absorber, the optimization objective for the collector performance was obtained theoretically, i.e., the maximization of the obtained entransy flow from solar radiation minus both the entransy loss due to heat loss to the environment and entransy dissipation due to the absorber's heat conduction. Furthermore, taking the fixed absorber material volume and the energy conservation equation as constraint conditions, the constrained extreme-value problem for optimal design of the thickness distribution was set up, and the optimization criterion of a uniform temperature gradient was deduced using variation methods.

According to the aforementioned optimization criterion, numerical simulations were carried out to optimize the thickness distribution of the absorber. The optimized results were remarkable. When the wind speed is $3 \mathrm{~m} / \mathrm{s}$, irradiation is $800 \mathrm{~W} / \mathrm{m}^{2}$, the ambient temperature is $300 \mathrm{~K}$, the mass flow rate is $0.003 \mathrm{~kg} / \mathrm{s}$ and the inlet temperature is $305 \mathrm{~K}$, and the collector efficiency can be enhanced by $8.8 \%$ through optimization, equivalent to a copper saving of $30 \%$. The paper also applied the thickness distribution optimized for wind speed of $3 \mathrm{~m} / \mathrm{s}$ in the heat transfer analysis for different wind speed conditions, and the collector efficiency was remarkably better than that for the absorber with uniform thickness. When the wind speed ranges from 1 to 4 $\mathrm{m} / \mathrm{s}$, the collector efficiency for the optimized thickness distribution is $8.3 \%-13.2 \%$ greater than that in the uniform-thickness case.

This work was supported by the National Natural Science Foundation of China (51006060).

1 Kalogirou S A. Solar Energy Engineering: Processes and Systems. Burlington, MA: Elsevier/Academic Press, 2009 
2 Dagdougui H, Ouammi A, Robba M, et al. Thermal analysis and performance optimization of a solar water heater flat plate collector: Application to T'etouan (Morocco). Renew Sust Energ Rev, 2011, 15: 630-638

3 Matrawy K K, Farkas I. Comparison study for three types of solar collector for water heating. Energy Conv Manag, 1997, 38: 861-869

4 Tsilingris P T. Back absorbing parallel plate polymer absorbers in solar collector design. Energy Conv Manag, 2002, 43: 135-150

5 Villar N M, Lopez J M C, Munoz F D, et al. Numerical 3-D heat flux simulations on flat plate solar collectors. Sol Energy, 2009, 83: 1086-1092

6 Luminosu I, Fara L. Determination of the optimal operation mode of a flat solar collector by exergetic analysis and numerical simulation. Energy, 2005, 30: 731-747

7 Farahat S, Sarhaddi F, Ajam H. Exergetic optimization of flat plate solar collectors. Renew Energy, 2009, 34: 1169-1174

8 Suzuki A, Okamura H, Oshida I. Application of exergy concept to the analysis of optimum operating conditions of solar heat collectors. J Sol Energy Eng Trans-ASME, 1987, 109: 337-342

9 Cervantes J G, Torres-Reyes E. Experiments on a solar-assisted heat pump and an exergy analysis of the system. Appl Therm Eng, 2002, 22: 1289-1297

10 Kara O, Ulgen K, Hepbasli A. Exergetic assessment of direct-expansion solar-assisted heat pump systems: Review and modeling. Renew Sust Energ Rev, 2008, 12: 1383-1401

11 Guo Z Y, Zhu H Y, Liang X G. Entransy - A physical quantity describing heat transfer ability. Int J Heat Mass Transf, 2007, 50: 2545-2556

12 Guo Z Y, Cheng X G, Xia Z Z. Least dissipation principle of heat transport potential capacity and its application in heat conduction op- timization. Chin Sci Bull, 2003, 48: 406-411

13 Chen Q, Zhu H Y, Pan N, et al. An alternative criterion in heat transfer optimization. Proc R Soc A-Math Phys Eng Sci, 2011, 467: 1012-1028

14 Cheng X G. Entransy and its applications in heat transfer optimization (in Chinese). Doctoral Dissertation. Beijing: Tsinghua University, 2004

15 Chen Q, Wang M, Pan N, et al. Irreversibility of heat conduction in complex multiphase systems and its application to the effective thermal conductivity of porous media. Int J Nonlinear Sci Numer Simul, 2009, 10: 57-66

16 Meng J A, Liang X G, Li Z. Field synergy optimization and enhanced heat transfer by multi-longitudinal vortexes flow in tube. Int $\mathbf{J}$ Heat Mass Transf, 2005, 48: 3331-3337

17 Chen Q, Ren J X, Meng J A. Field synergy equation for turbulent heat transfer and its application. Int J Heat Mass Transf, 2007, 50: 5334-5339

18 Wu J, Liang X G. Application of entransy dissipation extremum principle in radiative heat transfer optimization. Sci China Ser E-Technol Sci, 2008, 51: 1306-1314

19 Kazeminejad H. Numerical analysis of two dimensional parallel flow flat-plate solar collector. Renew Energy, 2002, 26: 309-323

20 Oliver D R. The effect of natural convection on viscous-flow heat transfer in horizontal tubes. Chem Eng Sci, 1962, 17: 335-349

21 Marcos S M, Bergles A E. Experimental investigation of combined forced and free laminar convection in horizontal tubes. J Heat Transf-Trans ASME, 1975, 97: 212-219

22 Bergles A E, Simonds R R. Combined forced and free convection for laminar flow in horizontal tubes with uniform heat flux. Int $\mathrm{J}$ Heat Mass Transf, 1971, 14: 1989-2000

Open Access This article is distributed under the terms of the Creative Commons Attribution License which permits any use, distribution, and reproduction in any medium, provided the original author(s) and source are credited. 